\section{A pronúncia da lateral /1/ no Sudoeste do estado do Paraná}

The pronunciation of lateral $/ l$ in the Southwest of Paraná state

Susiele MACHRY DA SILVA (UTFPR) susiele.machry@gmail.com

Eduarda Rocha BORGHELOTT (UTFPR) eduardaborg@outlook.com

Vanessa de ANDRADE (UTFPR) vanessa_andradde@hotmail.com

Recebido em: 30 de out. de 2019. Aceito em: 30 de jan. de 2020.
MACHRY DA SILVA, Susiele;

BORGHELOTT, Eduarda Rocha;

ANDRADE, Vanessa de. A pronúncia

da lateral /l/ no Sudoeste do estado do

Paraná. Entrepalavras, Fortaleza, v.

10, n. 1, p. 59-76, jan-abr/2020. DOI:

10.22168/2237-6321-11753.
Resumo: Vinculada à Sociolinguística Quantitativa (LABOV, 1972), esta pesquisa versa sobre os processos de variação que incidem sobre a realização do /l/ pósvocálico, em formas como balde e sal, por exemplo. A partir de uma amostra de dados de três cidades da região sudoeste do estado do Paraná: Pato Branco, Francisco Beltrão e Dois Vizinhos, o estudo investiga as possibilidades de realização do /l/ na forma vocalizada [w], velarizada [ł], alveolar [1], ou ainda, como tepe [r]. A amostra foi obtida por meio da realização de instrumentos que contemplavam nomeação, descrição de imagens, leitura de frases e entrevista. Ao todo foram obtidos dados de fala de 08 informantes de cada cidade, estratificados pelas seguintes variáveis sociais: cidade e escolaridade. Os resultados indicam haver, na região, a predominância da forma plena da lateral como alveolar [1], mas há também registros das formas vocalizadas [w], velarizadas [ł], e ainda do uso da variante tepe $[r]$ ou retroflexa.

Palavras-Chave: Variação. /l/ Pósvocálico. Região Sudoeste-PR. 
V. $10(1)$

$59-76$

jan-abr

2020

Abstract: Linked to Quantitative Sociolinguistics (LABOV, 1972), this research approaches the processes of variation that affect the realization of /l/ post-vowel, in ways like balde and sal, for example. From a sample of data from three cities of southwestern Paraná state: Pato Branco, Francisco Beltrão and Dois Vizinhos, the study investigates the possibilities of performing /l/ in vocalized form [w], velarized [ł], honeycomb [1], or even as tepe [r]. The sample was obtained by performing instruments that included naming, image description, sentence reading, and interview. All speech data were obtained from 08 informants from each city, stratified by social variables: city, education and gender. The results indicate that there is a predominance of full lateral shape in the region as alveolar [1], but there are also records of the vocalized [w], velarized [ $\mathrm{t}$ ] forms, and also the use of the tepe variant [r] or retroflex.

Keywords: Variation. / l / Post-vocalic. Southwest Region-PR.

\section{Introdução}

A Sociolinguística Quantitativa ou Teoria da Variação, que segue da proposta laboviana na década de 60, trabalha a correlação de fatores linguísticos e sociais no estudo da língua, a partir de dados reais de fala. Ao considerar a variação como inerente à língua, os estudos vinculados à Sociolinguística procuram explicar a sistematização da forma como se implementam os processos de variação em comunidades de fala e como estes podem engatilhar mudanças linguísticas, a partir da observação dos diferentes estados da língua (WEINREICH; LABOV; HERZOG, 2006 [1968]).

Com a proposta de estudo da realização da lateral pós-vocálica /l/ na região sudoeste do estado do Paraná, esta pesquisa se insere no âmbito da Sociolinguística Quantitativa (ou Teoria da Variação), tendo por finalidade verificar quais formas se apresentam como alternativas na fala dos moradores desta região, bem como os fatores que podem contribuir para a escolha do falante por uma forma em detrimento de outra.

Levando em consideração tanto o processo histórico-social das comunidades investigadas, formadas por imigrantes em sua maioria descendentes de italianos, alemães e poloneses, bem como as diferenças de comportamento da lateral pós-vocálica no sul do Brasil, o estudo foi motivado pela perspectiva do entendimento atual do processo nas três cidades (Francisco Beltrão, Pato Branco e Dois Vizinhos) que fazem parte da região sudoeste, interior do Paraná.

Tendo como base as possíveis variantes mais suscetíveis de ocorrerem na realização da lateral pós-vocálica /l/ na região Sul do Brasil (QUEDNAU, 1993; DAL MAGO, 1998; ESPIGA, 1997; 
COLLISCHONN; QUEDNAU, 2009; BATTISTI; MORAS, 2016, entre outros), são consideradas nesta pesquisa as realizações de /l/ como: (1) forma vocalizada (legaw; awguma); (2) preservação da lateral plena (legal; alguma); (3) rotacismo - realização como tepe ou retroflexo (legar; arguma) ${ }^{1}$; (4) forma velarizada (legał; ałguma). A ocorrência de variantes da lateral é investigada nas posições de coda medial no interior do vocábulo (como em balde), ou, em coda final, em final de vocábulo (como em sal).

A forma vocalizada [w] é apontada como predominante no português brasileiro (QUEDNAU, 1993; TASCA, 1999; ESPIGA, 2001, 2002; HORA, 2006; SÁ, 2006; COLLISCHONN; QUEDNAU, 2009; PINHO; MARGOTTI, 2010; BATTISTI; MORAS, 2016, entre outros). A realização da lateral na forma vocalizada [w] é, de acordo com Sá (2006), característica do português falado no Brasil. Esta constitui uma variante historicamente presente na língua, havendo registros de transformações de $\mathbf{l}$ para $\mathbf{u}$ na passagem do latim clássico para o latim vulgar (SILVA NETO, 1970). No português do Brasil, o uso da variante vocalizada distingue-se, assim, do uso mais velarizado da lateral no português europeu.

Mattoso Camara (2007), na descrição do português brasileiro, registra que, na produção do /l/ pós-vocálico, há um movimento da ponta da língua junto aos dentes, acompanhado de um levantamento do dorso da língua junto ao véu palatino. Nesse processo, a produção vocalizada [w] se dá quando

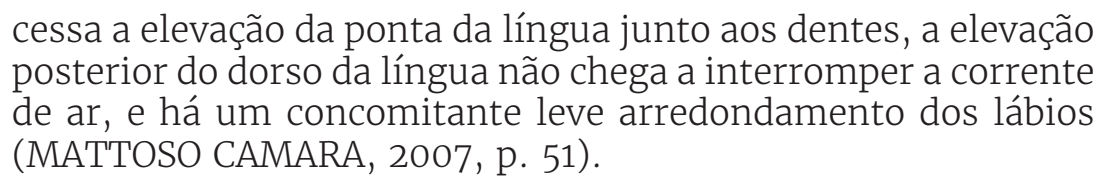

Como resultado, aponta o autor, chega-se a um /u/ assilábico, assim mal se torna homônimo de mau, e vil de viu, como processo que se caracteriza como neutralização.

Na região sul, mais diretamente foco desta investigação, não obstante, são também observadas realizações da lateral como forma velarizada [ł] (ex.: sał, bałde), como tepe ou aproximante retroflexo (ex.: barde; bar̀de). Há ainda registros de casos com apagamento da lateral (ex. azu $\varnothing$ ), este em percentual baixo.

\footnotetext{
${ }^{1}$ Nesse processo outras possibilidades de realização de $r$ - como [h], [j], [h]; no entanto, observou-se apenas a realização do fenômeno por ocorrência da substituição de $/ 1 /$ por um r em coda, tepe ou retroflexo.
} 
V. $10(1)$

$59-76$

jan-abr

2020

A forma velarizada, isto é, da produção da lateral como [ł], é passível de ocorrer na região sul do Brasil (ESPIGA, 1997; 2001; 2002), especialmente nos dialetos fronteiriços, visto seu uso estar associado ao contato do português com o espanhol, e também a outras influências dialetais decorrentes da formação étnica da região no contato com alemães e italianos. O autor sugere ainda que nesses dialetos pode predominar a variante alveolar; nessas variedades a implementação da mudança, ou a modificação de /l/ para a forma mais vocalizada, como em outras regiões do Brasil, ocorreria em um processo mais lento, havendo estágios intermediários entre uma e outra forma (como exemplo, cita a forma velarizada e labializada [lw] que se situaria entre a velar [ł] e a semivogal $[\mathrm{w}])$.

Assim, ainda que pesquisas como Collischonn e Quednau (2009) e Hahn e Quednau (2007) apontem para o uso predominante da forma vocalizada em cidades do Paraná, como Londrina e Pato Branco, este estudo parte da hipótese de que a região investigada apresente o uso de outras variantes, dentre elas o rotacismo, a própria preservação da alveolar plena, e ainda casos de velarização (nos falantes mais velhos principalmente). A hipótese de preservação da lateral também se sustenta com base em Dal Mago (1998) que, em sua pesquisa, realizada com dados do VARSUL (1990) aponta que, em cidades como Pato Branco, os informantes se mantêm entre a preservação da lateral e a vocalização. A hipótese do uso do rotacismo se sustenta no fato de ser este um processo histórico e antigo, bastante característico de regiões do Paraná pelos contatos dos moradores dessa região com tropeiros (PINHO; MARGOTTI, 2010).

\section{Metodologia}

Região Sudoeste - cidades investigadas

Este estudo faz parte de um projeto de mapeamento sociolinguístico do sudoeste do Paraná, iniciado em 2017, que tem por objetivo mapear os principais usos linguísticos da região. Para esta pesquisa, realizamos um recorte de três cidades para compor a amostra. A mesorregião sudoeste paranaense, de acordo com dados IBGE (2016), é constituída por 42 munícipios. Essa região é formada, segundo Ortolan (2007), por municípios que se assemelham quanto às suas características naturais e formação histórica. O território foi 
se formando pela ocupação dos caboclos e, mais tarde, pela chegada de imigrantes. Fazem parte desta região, dentre outros municípios, Francisco Beltrão, Pato Branco e Dois Vizinhos, selecionados para a constituição da amostra deste estudo.

Figura 1 - Região Sudoeste do Paraná - localização das cidades

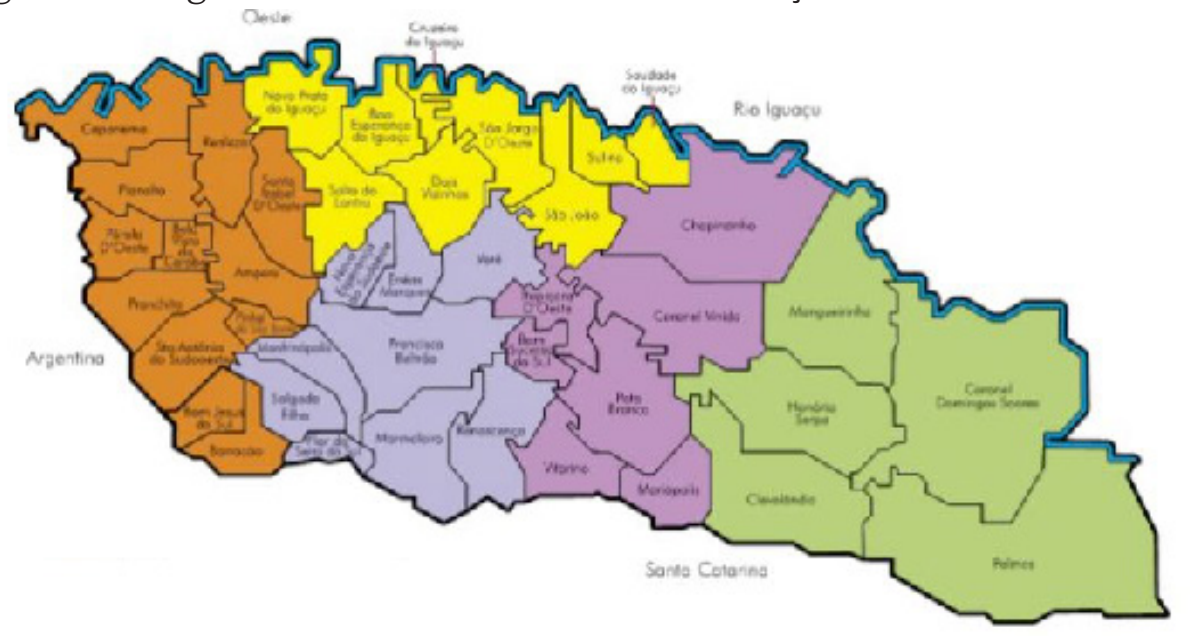

Fonte: http://paginapessoal.utfpr.edu.br/fernandoramme/mapas/sudoeste.

Os municípios de Francisco Beltrão, Pato Branco e Dois Vizinhos são formados em grande parte por imigrantes de descendência europeia (italiana, alemã e polonesa, principalmente), vindos dos estados do Rio Grande do Sul e de Santa Catarina. A região possui como base econômica a produção agroindustrial, baseada nas atividades de agricultura, agropecuária, indústria e comércio. Especialmente as cidades de Francisco Beltrão e Pato Branco se destacam, atualmente, pelo rápido crescimento populacional e desenvolvimento. O crescimento desses municípios se justifica no sentido de constituírem polos principais de educação, saúde (entre outros) de suas microrregiões (ORTOLAN, 2007).

\section{Informantes}

Ao todo, são 24 informantes que compõem a amostra, sendo 08 de cada cidade. Esses informantes residem na área urbana de seus municípios e foram aleatoriamente selecionados de acordo com uma estratificação inicial por cidade e escolaridade. O Quadro 1, a seguir, mostra a estratificação dos informantes. 
V. $10(1)$ $59-76$ jan-abr 2020

Quadro 1 - Estratificação dos informantes

\begin{tabular}{|c|c|c|c|c|}
\hline \multirow{2}{*}{$\begin{array}{c}\text { Francisco } \\
\text { Beltrão }\end{array}$} & \multicolumn{2}{|c|}{ Ensino Fundamental } & \multicolumn{2}{|c|}{ Ensino Médio } \\
\hline & $19-50$ anos & 50 anos ou + & $19-50$ anos & 50 anos ou + \\
\hline F & 1 & 2 & 1 & 1 \\
\hline M & & 2 & 1 & \\
\hline \multirow{2}{*}{ Pato Branco } & \multicolumn{2}{|c|}{ Ensino Fundamental } & \multicolumn{2}{|c|}{ Ensino Médio } \\
\hline & $19-50$ anos & 50 anos ou + & $19-50$ anos & 50 anos ou + \\
\hline $\mathrm{F}$ & 2 & 1 & 1 & \\
\hline M & & 1 & 2 & 1 \\
\hline \multirow{2}{*}{ Dois Vizinhos } & \multicolumn{2}{|c|}{ Ensino Fundamental } & \multicolumn{2}{|c|}{ Ensino Médio } \\
\hline & $19-50$ anos & 50 anos ou + & 19 - 50 anos & 50 anos ou + \\
\hline $\mathrm{F}$ & 1 & 1 & 1 & 1 \\
\hline M & 1 & 1 & 2 & \\
\hline
\end{tabular}

Fonte: elaborado pelos autores.

Essa estratificação inicial foi pautada nas variáveis cidade e escolaridade, buscando compor uma amostra mais homogênea no que se refere a essas variáveis. Os informantes possuem idade entre 19 e 80 anos, compreendendo basicamente duas faixas etárias, mais jovens, idade entre 19 e 50 anos, e uma faixa etária de mais velhos, acima de 50 anos. Embora não se tenha, no atual momento da pesquisa, para todas as cidades, um número idêntico para cada uma dessas faixas etárias, visto ser a idade variável que pode influenciar no comportamento, tevese o cuidado de selecionar informantes das duas gerações. Ao serem convidados para participar da pesquisa, os informantes, se de acordo, assinavam a um Termo de Consentimento Livre e Esclarecido².

\section{Instrumentos}

Como parte de um projeto maior, a pesquisa contou com diferentes etapas na realização das entrevistas. A coleta foi realizada buscando aliar modelos da Sociolinguística, como a entrevista de fala espontânea, com propostas de outros instrumentos. Para esta pesquisa, utilizou-se da nomeação e descrição de imagens, leitura, memorização de frases, conversa informal sobre temas, como: educação, infância, viagens, entre outros. A utilização de diferentes técnicas para a realização das entrevistas teve o propósito de obter uma amostra de dados semelhante para cada cidade, tornar as entrevistas menos cansativas e garantir a produção de itens lexicais específicos.

${ }^{2}$ Esta pesquisa possui registro e aprovação do Comitê de Ética em Pesquisa, CAAE: 60270316.5.0000.5547 
A coleta dos dados aconteceu entre os anos de 2018 e 2019. As entrevistas foram gravadas utilizando-se de um dispositivo gravador de voz (ICD - PX 720 - Sony), algumas na casa dos informantes e outras em laboratório da Universidade. Utilizou-se, ainda, um computador portátil para apresentação das imagens e frases. A Figura 2 exemplifica imagens que foram apresentadas aos participantes.

Figura 2 - Exemplificação dos experimentos de nomeação e descrição de imagens

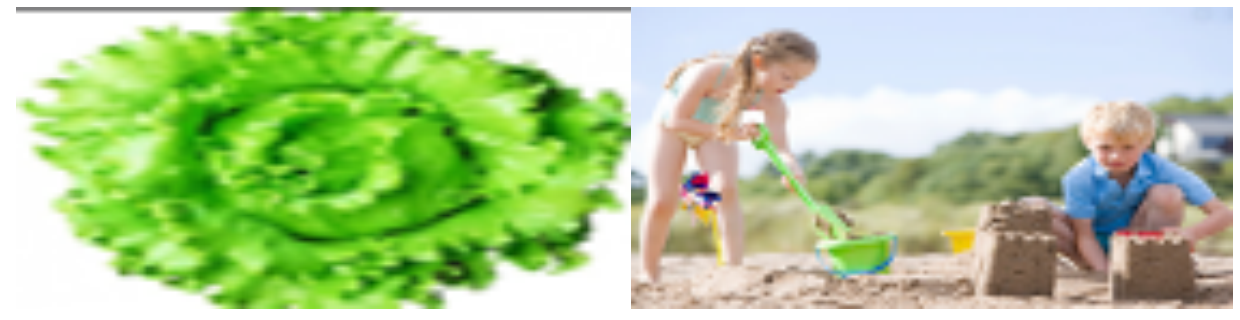

Fonte: Banco de imagens Shutterstock.

Na etapa 1, descrição de imagens, o participante era convidado a nomear o que estava visualizando (ex: alface). Na etapa 2, procurouse utilizar imagens contextualizadas, nesse caso, na intenção de o informante descrever detalhadamente (objetos, cores, local) e, também, de conversar sobre algum fato ou situação a que a imagem poderia remeter. Na sequência dessas duas etapas, foi aplicado um instrumento com frases (ex.: A roupa está no varal), em que o informante era convidado a ler, memorizar a frase, e reproduzi-la. Ambos os experimentos, com imagens e com frases, continham diferentes itens lexicais (não apenas os que são alvo de análise neste estudo), contemplando outros processos, assim como itens na função de distratores. A última etapa era realizada como forma de conversa, mais próxima da fala espontânea, sobre temas escolhidos pelo informante. Nesta etapa, o pesquisador buscava auxiliar com perguntas e comentários, suscitando a fala espontânea.

Decisões de análise

Os dados foram analisados com auxílio do programa Rbrul (versão 3.6.1), desenvolvido por Daniel Johson (2009). A variável dependente incluiu as seguintes possiblidades de realização do /l/ em coda:

(1) Preservação da lateral alveolar (alface; sol);

(2) Realização da lateral velarizada (ałface; soł);

(3) Realização de rotacismo (arface; sor);

(4) Vocalização (awface; sow). 
V. $10(1)$

$59-76$

jan-abr 2020

Outros casos possíveis, a exemplo do apagamento, não foram considerados neste estudo. Foram privilegiadas nesta proposta, por questão de delimitação, as variáveis independentes sociais, sendo incluídas apenas as variáveis linguísticas vogal precedente e posição no interior do vocábulo. O Quadro 2 apresenta as variáveis incluídas na análise.

Quadro 2 - Resumo das variáveis investigadas

\begin{tabular}{|ll|l|}
\hline \multicolumn{2}{|c|}{ Variáveis sociais } & \multicolumn{1}{c|}{ Variáveis linguísticas } \\
\hline Escolaridade & $\begin{array}{l}\text { Fundamental } \\
\text { Médio/superior }\end{array}$ & Vogal precedente - a, e, i, $\varepsilon$, o, o, u \\
\hline Sexo & $\begin{array}{l}\text { Masculino } \\
\text { Feminino }\end{array}$ & $\begin{array}{l}\text { Posição na palavra } \\
\text { Interior do vocábulo } \\
\text { Final de palavra }\end{array}$ \\
\hline Idade & $\begin{array}{l}\text { Até 50 anos } \\
\text { Mais de 50 anos }\end{array}$ & \\
\hline Cidade & $\begin{array}{l}\text { Pato Branco } \\
\text { Francisco Beltrão } \\
\text { Dois Vizinhos }\end{array}$ & \\
\hline Etnia & $\begin{array}{l}\text { Alemã } \\
\text { Italiana } \\
\text { Polonesa } \\
\text { Brasileira } \\
\text { Espanhola }\end{array}$ & \\
& & \\
\hline
\end{tabular}

Fonte: elaborado pelos autores.

As variáveis investigadas tomaram como base estudos anteriores sobre o processo (HAHN; QUEDNAU, 2007; QUEDNAU; COLLISCHONN, 2009, entre outros), mas foram consideradas também as características da pesquisa realizada, tais como: região, instrumentos aplicados e dados obtidos.

\section{Resultados e discussões}

Aplicação do processo nas cidades investigadas

O levantamento inicial dos dados quanto ao uso das variantes, incluindo na análise as três cidades investigadas, permite observar a predominância da lateral alveolar (com percentual de 71,79\%). No entanto, os dados apontam também para a ocorrência da vocalização (percentual de 15,38\%), da lateral velarizada (percentual de 8,20\%) e do rotacismo (percentual de 4,50\%). 
Gráfico 1 - Aplicação das variantes nas três cidades

Valores de aplícação de cada variante

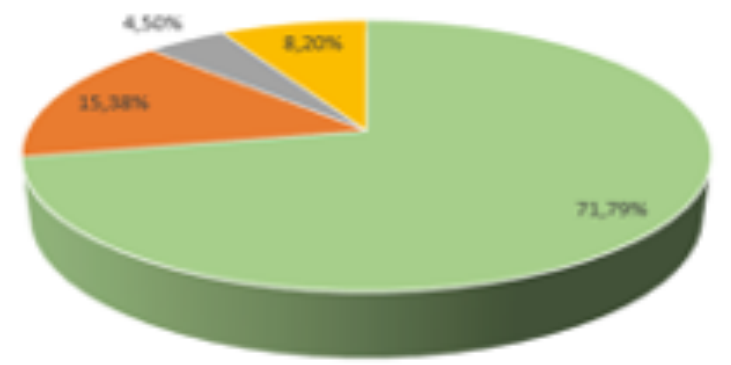

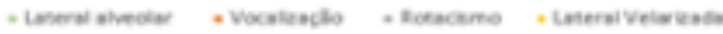

Fonte: elaborado pelos autores.

Por esses dados, percebe-se que, na região, ainda se mantém o uso da forma alveolar. Este predomínio da alveolar não é condizente com o que aponta a pesquisa de Collischonn e Quednau (2009), a partir de dados do VARSUL, em relação à suscetibilidade de ocorrência da vocalização para cidades do Paraná, Pato Branco (91\%) e Londrina (80\%). Chama, assim, atenção o valor de apenas 15,38\% de aplicação da forma vocalizada. Embora a hipótese inicial fosse de que nas cidades investigadas se encontrariam ocorrências de outras variantes, pelas características da região, formação étnica, eram esperados valores mais altos de aplicação da forma vocalizada.

O fato de ainda prevalecer na região a lateral alveolar mostra, não obstante, conformidade com a predominância dessa variante em regiões do Sul (como mostram Pinho e Margotti (2010)). De acordo com os autores, os percentuais mais altos de aplicação da vocalização estariam concentrados na região noroeste do Paraná. A preservação da lateral na região sul do Brasil poderia, por hipótese, ter relação com contatos linguísticos, como o espanhol, tomando por referência a pesquisa de Espiga (1997, 2002). Pato Branco e Francisco e Beltrão são cidades relativamente próximas da fronteira com a Argentina. O uso da alveolar sugere também ter relação com a formação étnica da região, em sua maioria descendentes de italianos e alemães (o que se discutirá mais adiante).

A partir desses dados iniciais, realizou-se, antes do desenvolvimento da estatística, o levantamento dos percentuais de uso de cada variante por cidade. Percentuais mais altos do uso da lateral alveolar são observados em Pato Branco (percentual de 82,64\%) e Dois Vizinhos (73,95\%). Francisco Beltrão apresenta 56,30\% de manutenção da alveolar. Esses dados revelam também ser Francisco Beltrão a cidade 
V. 10 (1) 59-76 jan-abr 2020

que mais apresenta uso das formas variantes, como a vocalização (percentual de 18,46\%), a realização da lateral velarizada (14,41\%) e o rotacismo (10,81\%). A vocalização é também observada em Dois Vizinhos (com percentual de 18,60\%, semelhante ao que se observa para Francisco Beltrão). Pato Branco apresenta 10,18\% de uso da forma vocalizada e apenas 1 ocorrência de rotacismo.

Tabela 1 - Distribuição das variantes por cidade

\begin{tabular}{c|c|c|c|c|c}
\hline Cidade & $\begin{array}{c}\text { Número de } \\
\text { dados }\end{array}$ & $\begin{array}{c}\text { Lateral } \\
\text { alveolar }\end{array}$ & Vocalização & Rotacismo & $\begin{array}{c}\text { Lateral } \\
\text { velarizada }\end{array}$ \\
\hline $\begin{array}{c}\text { Francisco } \\
\text { Beltrão }\end{array}$ & 222 & $56,30 \%$ & $18,46 \%$ & $10,81 \%$ & $14,41 \%$ \\
\hline Pato Branco & 265 & $82,64 \%$ & $10,18 \%$ & 1 ocorrência & $6,79 \%$ \\
\hline Dois Vizinhos & 215 & $73,95 \%$ & $18,60 \%$ & $3,25 \%$ & $4,18 \%$ \\
\hline
\end{tabular}

Fonte: elaborada pelos autores.

Observa-se, frente aos dados, que a cidade de Francisco Beltrão mostra um comportamento diferente na comparação com Pato Branco e Dois Vizinhos, principalmente no que condiz ao uso da variante rotacismo (com 10,81\%) e da lateral velarizada (14,41\%). O rotacismo, de acordo com pesquisas anteriores (COSTA, 2007; ALTENHOFEN et al., 2002), é uma variante associada ao falar rural, estando também mais presente na fala de informantes mais velhos e com baixa escolaridade. A lateral velarizada é verificada mais precisamente nas regiões de contato com o espanhol (ESPIGA, 1997, 2002), mas seu uso na comunidade pode também estar associado à descendência étnica dos participantes, em sua maioria alemães e italianos. Este uso pode também estar prevalecendo na fala de informantes com mais idade.

Por outro lado, o uso da forma vocalizada [w] estaria, em concordância com as tendências atuais de direcionamento do processo, a se encaminhar para maiores índices de aplicação entre os mais jovens, vindo a substituir a alveolar e as variantes de rotacismo e lateral velarizada (usadas pelas gerações mais velhas, questão a investigar). Esse processo estaria acontecendo de forma lenta e gradativa, não na mesma velocidade atestada em outras regiões do Brasil, em que a forma vocalizada já é predominante. Tais indicativos vão ao encontro do que sugere Espiga (2002) sobre a implementação da mudança:

em geral, as pesquisas mostram que a mudança progride, mas que são diferentes o ritmo de implementação de cada processo e o comportamento dos fatores que o condicionam, entre uma região e outra (ESPIGA, 2002, p. 54). 
Condicionamentos linguísticos e sociais

Para as rodadas ou testes estatísticos que seguem a partir do levantamento inicial dos dados, por se estar diante de uma variável dependente com mais de dois fatores, nominal, foi aplicado o modelo de regressão multimodal, nesse caso, considerando um dos fatores como controle (optou-se pela forma alveolar predominante), em relação aos demais fatores (rotacismo, velar e vocalizada). Após testes e cruzamentos, uma rodada inicial foi realizada, com amálgama na variável vogal precedente (juntando e - $\varepsilon$, e o - o) e exclusão das formas com apagamento, não alvo de análise neste estudo. Nessa primeira rodada, o programa selecionou as variáveis sexo, cidade, etnia e vogal precedente.

Antes de reportar os resultados das demais variáveis, apresentam-se os dados obtidos para a variável cidade, os quais reforçam (conforme ilustra a Tabela 2) os dados da Tabela 1, seção anterior, que indicam ser Francisco Beltrão a cidade que mais favorece a aplicação dos processos de vocalização, rotacismo e lateral velarizada. A cidade de Pato Branco, diferentemente, é a que mais tende a preservar a lateral alveolar.

Tabela 2 - resultados para a variável cidade

\begin{tabular}{c|c|c|c|c}
\hline \multicolumn{1}{c|}{ Fator } & Total de dados & Logodss & \% & Peso relativo \\
\hline Francisco Beltrão & 222 & 0.887 & $44 \%$ & 0,71 \\
\hline Pato Branco & 265 & -0.678 & $17 \%$ & 0,33 \\
\hline Dois vizinhos & 215 & -0.209 & $26 \%$ & 0,45 \\
\hline Fonte:
\end{tabular}

Fonte: elaborada pelos autores.

A variável vogal precedente (Tabela 3) foi a única linguística selecionada nesta rodada, mostrando favorecimento para aplicação dos processos de vocalização, rotacismo e lateral velarizada com contexto precedente vogal "a" (ex.: balde, sal) - 0,58 de peso relativo. A vogal "i" com menor número de ocorrência (11 dados, a exemplo de "fácil", "inútil"), com peso relativo 0,55 (próximo ao ponto neutro), é o segundo contexto que se mostra mais favorável. As vogais "e" e "o" mostram valores muito próximos ao ponto neutro, enquanto a vogal "u" parece desfavorecer a aplicação desses processos (0,35 de peso relativo). 
V. 10 (1) 59-76 jan-abr 2020

Tabela 3 - Vogal Precedente

\begin{tabular}{c|c|c|c|c}
\hline Fator & Total de dados & Logodss & \% & Peso relativo \\
\hline $\mathrm{A}$ & 436 & 0.321 & $32 \%$ & 0,58 \\
\hline $\mathrm{i}$ & 11 & 0.204 & $27 \%$ & 0,55 \\
\hline $\mathrm{e}$ & 29 & 0.142 & $27 \%$ & 0,53 \\
\hline $\mathrm{o}$ & 140 & -0.149 & $25 \%$ & 0,48 \\
\hline $\mathrm{u}$ & 86 & -0.618 & $14 \%$ & 0,35 \\
\hline
\end{tabular}

Fonte: elaborada pelos autores.

Os resultados para a variável demonstram certa conformidade com pesquisas anteriores. Hora (2006), a exemplo, aponta os contextos com vogais anteriores ou a central (a) como mais propensos à ocorrência de vocalização. Vogais posteriores, na pesquisa do autor, parecem favorecer o apagamento. Neste estudo foram obtidos apenas 03 casos de apagamento (ocorreram nas formas "azul", "anzol" e "fácil"), excluídos da análise. A vogal central "a" mostra também favorecer a vocalização no estudo de Hahn e Quednau (2007), em Londrina-PR.

Ainda que a vogal precedente represente ter papel para a aplicação dos processos, as variáveis sociais tendem a ser os gatilhos principais. Processos como vocalização e rotacismo, de acordo com pesquisas anteriores (DAL MAGO, 1998; COLLISCHONN; QUEDNAU, 2009; COSTA, 2007), têm relação com variáveis sociais. Ao verificar o papel da idade e da escolaridade, por exemplo, parece que há um direcionamento de a vocalização estar presente nos informantes mais jovens, com mais escolarização, enquanto o rotacismo estaria presente nos falantes mais velhos, com menor escolarização. No estudo em questão, o programa selecionou, nessa primeira rodada, as variáveis sexo, cidade e etnia. Surpreendentemente, as variáveis faixa etária e escolaridade não foram selecionadas.

Para a variável sexo (Tabela 4), os resultados indicam ser os homens os que menos preservam a lateral alveolar, com peso relativo um pouco acima de .50. Mulheres, por sua vez, parecem fazer mais o uso da alveolar, com menor propensão para a vocalização, o rotacismo ou a forma velarizada.

Tabela 4 - Sexo

\begin{tabular}{c|c|c|c|c}
\hline Fator & Total de dados & Logodss & $\%$ & Peso relativo \\
\hline Masculino & 330 & 0.241 & $31 \%$ & 0,56 \\
\hline Feminino & 372 & -0.241 & $26 \%$ & 0,44 \\
\hline
\end{tabular}

Fonte: elaborada pelos autores. 
A interpretação desses resultados, pelo entendimento deste estudo, deve ser tomada com cautela. Na sociolinguística, na linha laboviana, são muito comuns achados de que as mulheres se mostram mais sensíveis para pressões sociais, com isso usam menos formas estigmatizadas. A questão éque, no caso da variável sexo, esta não pode ser analisada, se não pela perspectiva dos papéis sociais de homens e mulheres, como bem aponta Luchesi (2012). Não se pode olhar isoladamente para uma variável. Para este autor, o papel do sexo "só pode ser compreendido à luz da compreensão do processo social como um todo" (LUCHESI, 2012, p. 799). Assim, comparativamente, é difícil encontrar qualquer generalização para o papel da variável, se não pelo olhar de outras questões sociais que envolvem a comunidade em estudo.

Nas comunidades investigadas, a própria história, formação são fatores que devem ser levados em conta. Ainda, cabe a reflexão de que estamos tratando de questões diferentes quanto à implementação dos processos em variação. Tem-se, por um lado, na interpretação que segue de Labov (1972), um processo de mudança do tipo de cima para baixo, como a vocalização (variante não estigmatizada, já mais consolidada na língua), e, por outro, um processo do tipo de baixo para cima, como o rotacismo, variante que tende a ser mais estigmatizada, com usos sociais associados a zonas rurais, falantes com menos escolaridade.

As cidades investigadas constituem centros urbanos de formação recente, que foram crescendo gradativamente a partir da migração de trabalhadores rurais, primeiramente oriundos dos estados de Santa Catarina e Rio Grande do Sul, e, mais atualmente, de moradores das áreas rurais que migram para os centros urbanos. Muitos desses residentes possuem descendência alemã e italiana.

Diante desses fatos, não se pode negar o possível efeito dessa formação histórico-social das comunidades no comportamento linguístico. A variável etnia, também selecionada nessa primeira rodada, parece fortalecer essa hipótese (Tabela 5), indicando a maior probabilidade de ocorrência dos processos entre italianos e alemães.

Tabela 5 - Etnia

\begin{tabular}{c|c|c|c|c}
\hline Fator & Total de dados & Logodss & \% & Peso relativo \\
\hline Italianos & 355 & 0.499 & $28 \%$ & 0,62 \\
\hline Alemães & 29 & 0.313 & $37 \%$ & 0,57 \\
\hline Poloneses & 71 & 0.279 & $36 \%$ & 0,56 \\
\hline Brasileiros & 214 & -0.018 & $28 \%$ & 0,49 \\
\hline Espanhóis & 33 & -1.073 & $12 \%$ & 0,25 \\
\hline
\end{tabular}

Fonte: elaborada pelos autores. 
V. 10 (1) 59-76 jan-abr 2020

Nota-se que italianos são os que fazem uso de variantes como a vocalização, o rotacismo, a lateral velarizada (peso relativo, 0,62). Alemães e poloneses também mostram tendência ao uso, com 0,57 e 0,56 , respectivamente, de peso relativo. Brasileiros apresentam valor próximo ao ponto neutro (0,49 de peso relativo); e espanhóis, bem abaixo ( 0,25 de peso relativo).

Com o propósito de observar com mais transparência o efeito das variáveis sociais em cada processo, vocalização, lateral velarizada e rotacismo, optou-se por fazer uma nova rodada, excluindo da variável dependente os fatores a não serem analisados. Assim, foram 03 rodadas: lateral alveolar X vocalização, lateral alveolar X rotacismo e lateral alveolar X lateral velarizada. Na primeira rodada, em que apenas incluímos a vocalização, foram selecionadas as variáveis sexo, escolaridade e etnia.

Tabela 6 - Vocalização: variáveis sociais

\begin{tabular}{c|c|c|c|c|c|c|c|c}
\hline \multicolumn{4}{c|}{ Sexo } & \multicolumn{3}{c|}{ Escolaridade } & \multicolumn{3}{c}{ Etnia } \\
\hline Fator & $\mathbf{\%}$ & $\mathbf{P R}$ & & $\mathbf{\%}$ & $\mathbf{P R}$ & Fator & $\mathbf{\%}$ & $\mathbf{P R}$ \\
\hline Feminino & 18 & 0,51 & $\begin{array}{c}\text { Ens. Médio/ } \\
\text { superior }\end{array}$ & 26 & 0,65 & Poloneses & 29 & 0,72 \\
\hline Masculino & 17 & 0,49 & $\begin{array}{c}\text { Ensino } \\
\text { Fundamental }\end{array}$ & 10 & 0,35 & Alemães & 34 & 0,65 \\
\hline \multicolumn{9}{c}{ Aplicação da vocalização nas três cidades } \\
investigadas = 15,38\%
\end{tabular}

Fonte: elaborada pelos autores.

Embora a variável sexo tenha sido selecionada nesta rodada, não há diferenças de comportamento entre homens e mulheres no que tange à produção da vocalização, estando os dois valores muito próximos ao ponto neutro. A variável escolaridade, não selecionada na primeira rodada (com os processos analisados conjuntamente), agora mostra ter efeito no processo de vocalização. Para essa variável, o resultado vem ao encontro do que apontam pesquisas anteriores (COLLISCHONN; QUEDNAU, 2009; HORA, 2006), reforçando a hipótese da relação entre escolaridade e produção da vocalização, sendo que, quanto maior a escolarização, maior a tendência da produção da variante vocalizada.

Quanto à variável etnia, verifica-se nessa rodada que são os poloneses ( $P R=0,72)$ e alemães ( $P R=0,65)$, os grupos que mais aplicam o processo, seguido dos brasileiros $(P R=0,55)$. Italianos e espanhóis 
mostram valores abaixo de 0,50. O fato de os italianos fazerem menos uso da vocalização encontra evidências em estudos anteriores (QUEDNAU, 1993).

$\mathrm{Na}$ rodada considerando apenas o processo de rotacismo, foram analisadas as cidades de Francisco Beltrão e Dois Vizinhos, já que Pato Branco teve uma única ocorrência e por isso foi excluído desta análise. O fator poloneses, na variável etnia, foi também excluído, por não ter nenhuma ocorrência. O programa selecionou as variáveis sociais faixa etária, escolaridade e etnia.

Tabela 7- Rotacismo: variáveis sociais

\begin{tabular}{c|c|c|c|c|c|c|c|c}
\hline \multicolumn{3}{c|}{ Faixa etária } & \multicolumn{3}{c|}{ Escolaridade } & \multicolumn{3}{c}{ Etnia } \\
\hline Fator & $\mathbf{\%}$ & $\mathbf{P R}$ & & $\mathbf{\%}$ & $\mathbf{P R}$ & Fator & $\mathbf{\%}$ & PR \\
\hline + de 50 & 33 & 0,56 & $\begin{array}{c}\text { Ensino } \\
\text { Fundamental }\end{array}$ & 26 & 0,62 & Alemães & 42 & 0,72 \\
\hline - de 50 & 21 & 0,44 & $\begin{array}{c}\text { Ensino Médio/ } \\
\text { Superior }\end{array}$ & 12 & 0,36 & Brasileiros & 31 & 0,62 \\
\hline
\end{tabular}

Fonte: elaborada pelos autores.

Os resultados, ao encontro das hipóteses iniciais quanto ao uso do rotacismo (COSTA, 2007), parecem comprovar estar o processo presente entre mais velhos e com menor escolaridade. Na variável faixa etária, observa-se que o rotacismo está mais presente entre os falantes mais velhos $(P R=0,56)$, com menor escolaridade - Ensino Fundamental $(\mathrm{PR}=0,62)$.

Quanto à variável etnia, o rotacismo parece estar mais presente entre os descentes alemães $(P R=0,72)$ e os brasileiros $(P R=$ $0,62)$. Italianos mostram valor próximo ao ponto neutro $(P R=0,52)$; e espanhóis, valor bem abaixo ( $P R=0,26)$.

Na terceira rodada, foi considerado apenas o processo de produção da lateral velarizada, mantendo as três cidades na análise. Nessa rodada, o fator alemães na variável etnia foi excluído por não apresentar para esse processo nenhuma ocorrência. Foram selecionadas nessa rodada as variáveis sociais escolaridade, etnia e faixa etária. 
V. $10(1)$ $59-76$ jan-abr 2020

Tabela 8 - Lateral velarizada: variáveis sociais

\begin{tabular}{c|c|c|c|c|c|c|c|c}
\hline \multicolumn{4}{c|}{ Escolaridade } & \multicolumn{3}{c|}{ Faixa Etária } & \multicolumn{3}{c}{ Etnia } \\
\hline Fator & $\mathbf{\%}$ & $\mathbf{P R}$ & & $\mathbf{\%}$ & $\mathbf{P R}$ & Fator & $\mathbf{\%}$ & $\mathbf{P R}$ \\
\hline Ensino Fundamental & 16 & 0,69 & +50 & 48 & 0,77 & Italianos & 42 & 0,87 \\
\hline $\begin{array}{c}\text { Ensino médio/ } \\
\text { superior }\end{array}$ & 12 & 0,30 & - de 50 & 0,4 & 0,22 & Espanhóis & 28 & 0,84 \\
\hline
\end{tabular}

Fonte: elaborada pelos autores.

O processo de velarização da lateral, semelhante ao observado para o rotacismo, parece estar presente nos falantes mais velhos, faixa etária acima de 50 anos $(P R=0,77)$, falantes com menor escolaridade $(P R=0,69)$. Nesse sentido, a variável, pouco recorrente na amostra, parece estar sendo usada ainda pelas gerações mais velhas, especialmente descendentes de italianos $(P R=0,87)$ e espanhóis $(P R=0,84)$. Observase ainda haver preferência pela forma velarizada, principalmente entre descendentes de italiano, o que sugere, com respaldo em Dal Mago (1998), que possa ter relação com a tendência da velarização nessa língua. A aplicação mais alta da forma velarizada em detrimento da forma vocalizada nesses grupos é condizente também com o que apontam dados das pesquisas de Quednau (1993), Tasca (1999), entre outros.

\section{Considerações finais}

Esta pesquisa teve o propósito de apresentar o comportamento da lateral /l/ em posição de coda nas cidades de Pato Branco, Francisco Beltrão e Dois Vizinhos, localizadas na região sudoeste do estado do Paraná. A pesquisa considerou quatro possibilidades na realização de /l/: (1) preservação da lateral; (2) vocalização; (3) rotacismo; e (4) lateral velarizada. Os resultados revelam haver, nas três cidades investigadas, propensão para a manutenção da lateral alveolar, com um índice maior da aplicação das variantes de vocalização, rotacismo e lateral velarizada na cidade de Francisco Beltrão. Pato Branco mostra ser a cidade com maior índice de preservação da lateral; Dois Vizinhos, por sua vez, mostra também essa predominância, mas apresenta também casos de vocalização.

Quanto aos condicionamentos linguísticos e sociais, fazse antes a ressalva de que este estudo não esgotou as possibilidades de análise, principalmente quanto a variáveis linguísticas, atendo-se, mais precisamente, a variáveis sociais. Assim, os resultados possíveis 
de relato para o contexto linguístico, a partir da seleção apenas da variável vogal precedente, é de que se observa o favorecimento de vogais anteriores e da vogal central "a" para aplicação do processo.

Dos resultados obtidos para as variáveis sociais investigadas, destacam-se duas direções principais: (i) estar o uso rotacismo e da lateral velarizada mais presente entre falantes mais velhos e com menor escolaridade; (ii) estar o uso da vocalização mais presente nos falantes mais jovens e com maior escolaridade. Ainda quanto à etnia, parece haver um favorecimento da aplicação da vocalização por poloneses e alemães; do rotacismo, por alemães e brasileiros; e da lateral velarizada, por italianos e espanhóis.

Ainda com as limitações deste estudo, que futuramente pode explorar outras variáveis, assim como trazer um conjunto maior de dados, incluindo outras cidades, o trabalho atual permite observar que a lateral alveolar tende a ser preservada. A vocalização, na região, parece representar um processo de aquisição lento e gradativo, com diferentes estágios em cada cidade. Por sua vez, os processos de rotacismo e lateral velarizada, usados ainda pelos falantes mais velhos, caminham gradativamente para o desaparecimento.

\section{Referências}

ALTENHOFEN, C.V. Áreas linguísticas do português falado no Sul do Brasil: um balanço das fotografias geolinguísticas do ALERS. In: VANDRESEN, Paulino. Variação e mudança no portuguếs falado na região Sul. Pelotas: EDUCAT, 2002. p. 115 - 145.

BATTISTI, E. Moras, V. T. A vocalização da consoante lateral em coda silábica em uma variedade de português brasileiro: análise sociolinguística em tempo real. Gragoatá, Niterói, n. 40, p. 90-112, 10 sem 2016.

COLLISCHONN, G; QUEDNAU, L. R. As laterais variáveis da região sul. In: BISOL, L; COLLISCHONN, G. (org). Português do sul do Brasil. Porto Alegre: EDIPUCRS, 2009. p. 152-173.

COSTA, L. T. Análise variacionista do rotacismo. Revista Virtual de Estudos da Linguagem - ReVEL, v. 5, n. 9, p. 1-29, ago. 2007.

DAL MAGO, D. O comportamento de /l/ pós-vocálico no sul do país. Working papers em linguística, UFSC, n. 2, p. 31-44, jul./dez. 1998.

ESPIGA, J. Influência do espanhol na variação da lateral posvocálica do português da fronteira. 1997. 194 f. Dissertação (Mestrado em Letras) Programa de Pós-Graduação em Letras, Universidade Federal de Pelotas, Pelotas, 1997.

ESPIGA, J. A lateral posvocálica na fronteira dos Campos Neutrais. Letras de Hoje, Porto Alegre, v. 37, n. 1, p. 49-68, 2002. 
V. $10(1)$ $59-76$ jan-abr 2020
ESPIGA, J. da R. O português dos campos neutrais: um estudo sociolingüístico da lateral posvocálica nos dialetos fronteiriços de Chuí e Santa Vitória do Palmar. 2001. 154 f. Tese (Doutorado em Linguística Aplicada) - Pontifícia Universidade Católica do Rio Grande do Sul, Porto Alegre, 2001.

HAHN, L. H; QUEDNAU, L. R. A lateral pós-vocálica no português de Londrinha: análise variacionista e estrutura silábica. Letras de Hoje, Porto Alegre, v. 42, n. 3, p.100-113, 2007.

HORA, D. Vocalização da lateral /l/: correlação entre restrições sociais e estruturais. SCRIPTA, Belo Horizonte, v. 9, n. 18, p. 29-44, 2006.

IBGE - INSTITUTO BRASILEIRO DE GEOGRAFIA E ESTATÍSTICA. 2016. Disponível em: https://cidades.ibge.gov.br/brasil/pr/francisco-beltrao/ panorama. Acesso em set. 2019.

JOHNSON, D. Getting of the GoldVarb Standard: introducing Rbrul for mixedeffects variable rule analysis. Language and Linguistics Compass, v. 3, n. 1 , 2009.

LABOV, W. Sociolinguistic Patterns. Philadelphia: University Pennsylvania Press, 1972.

LUCHESI, D. A Teoria da Variação Linguística: um balanço crítico. Estudos Linguísticos, São Paulo, v. 41, n. 2, p. 793-805, maio/ago. 2012.

ORTOLAN, Adrian A. Aspectos da construção histórica do sudoeste do Paraná e da cidade de Francisco Beltrão. Revista Faz Ciência, v. 9, n. 9, p.11-33, jan./ jul. 2007.

PINHO, A. J.; MARGOTTI, F. W. A variação da lateral posvocálica /l/ no português do Brasil. Working Papers linguística, Florianópolis, v. 11, n. 2, p. 67-88, 2010.

QUEDNAU, L. A lateral pós-vocálica no português gaúcho: análise variacionista e representação não-linear. 1993. 109 f. Dissertação (Mestrado em Letras) - Instituto de Letras, Universidade Federal do Rio Grande do Sul, Porto Alegre, 1993.

SÁ, E. J. O uso variável da lateral /l/ pós-vocálica em posição de coda em português e espanhol. Revista Virtual de Estudos da Linguagem. ReVEL, ano 4, n. 7, p. 1-9, ago. 2006.

SILVA NETO, S. História da Língua Portuguesa. Rio de Janeiro: Livros de Portugal, 1970.

TASCA, M. A lateral em coda silábica no Sul do Brasil. 1999. Tese (Doutorado em Linguística Aplicada) - Faculdade de Letras, Pontifícia Universidade Católica do Rio Grande do Sul, Porto Alegre, 1999.

WEINREICH, U.; LABOV, W. HERZOG, M. Fundamentos empíricos para uma teoria da mudança linguística. Tradução de Marcos Bagno; revisão técnica de Carlos Alberto Faraco. São Paulo: Parábola, 2006. 